\title{
Guidelines for Credentialing of Practitioners to Perform Endovascular Stent-Grafting of the Thoracic Aorta
}

\author{
Nicholas T. Kouchoukos, MD (Chair), Joseph E. Bavaria, MD, Joseph S. Coselli, MD, Ralph De La Torre, MD, \\ John S. Ikonomidis, MD, Riyad C. Karmy-Jones, MD, Robert Scott Mitchell, MD, Richard J. Shemin, MD, \\ David Spielvogel, MD, Lars G. Svensson, MD, and Grayson H. Wheatley, MD
}

Task Force on Endovascular Surgery, Workforce on Adult Cardiac Surgery, Council on Education and Member Services, The Society of Thoracic Surgeons, Chicago, Illinois

This document has been approved by The Society of Thoracic Surgeons and the American Association for Thoracic Surgery after thorough review, which included a notice and comment process.

This article is being co-published simultaneously in The Annals of Thoracic Surgery and The Journal of Thoracic and Cardiovascular Surgery.

Dr Bavaria discloses that he has a financial relationship with Cook Inc, W. L. Gore \& Associates Inc, and Medtronic USA Inc; Dr Coselli with Cook Zenith and Gore TAG; and Dr Svensson with Cook Inc.

When citing this document, please use the following citation format: Kouchoukos NT, Bavaria JE, Coselli JS, De La Torre R, Ikonomidis JS, Karmy-Jones RC, Mitchell RS, Shemin RJ, Spielvogel D, Svensson LG, Wheatley GH. Guidelines for credentialing of practitioners to perform endovascular stent-grafting of the thoracic aorta. J Thorac Cardiovasc Surg. 2006;131: $530-2$.

J Thorac Cardiovasc Surg 2006; 131:530-2 $0022-5223 / \$ 32.00$

Copyright $\odot 2006$ by The Society of Thoracic Surgeons and the American Association for Thoracic Surgery

doi:10.1016/j.jtcvs.2006.01.001

\section{Background}

Recent innovations in endovascular grafting technology have made the endovascular treatment of thoracic aortic aneurysm, dissection, and other thoracic aortic diseases a viable alternative to open surgical repair. Like many new surgical procedures, thoracic endovascular stent-grafting presents challenges to physicians who care for patients with thoracic aortic disease. When new surgical procedures are introduced, the pressure for rapid adoption can lead to deviations from the fundamental principles of physician education and training and from the established indications for operative intervention. These deviations may compromise the quality and safety of patient care.

As with any surgical procedure, appropriate management of the specific underlying disease process involves several distinct but interrelated components. First and foremost, the involved physicians must possess a broad understanding of the disease entity. Second, they must possess knowledge of, and expertise in, all of the available therapeutic options, including, but not limited to, the new technique that is being applied. They must be able to care for the treated patients in the post-procedural period and to deal with the potential complications of a specific therapy. Third, they must receive technique-specific training. To enable physicians to meet these basic requirements for thoracic endovascular grafting procedures and to become credentialed to perform them, specific criteria for all three of these categories must be established.

\section{Disease Process}

\section{Knowledge Base Recommendations}

In many patients, thoracic aneurysms, atherosclerotic disease, and aortic dissections involving the descending thoracic aorta coexist with other morbid conditions. This complexity is further heightened when the aortic disease involves the adjacent ascending aorta, aortic arch and abdominal aorta. Physicians who care for patients with diseases of the thoracic aorta should have completed an educational program that encompasses the longitudinal care of patients with major thoracic aortic disease. Physicians who are to be involved with endovascular stent-grafting procedures of the thoracic aorta should have more extensive experience. They should be involved in the evaluation and 
management of a minimum of 20 patients with diseases of the thoracic aorta in the two-year period immediately prior to application for privileges to perform these procedures. This could include experience accumulated in an Accreditation Council for Graduate Medical Education (ACGME)-approved cardiothoracic surgical training program. Physicians could obtain this experience independently or as part of a single specialty or multidisciplinary group.

Clinical expertise is achieved not only from experience but from continuing education. To this end, physicians who perform thoracic endovascular stent-grafting procedures should participate in accredited CME programs dedicated to this new technology. The participating physicians should also document the results of their clinical experience with the technique in an approved database. Preferably, this should be a regional or national database such as those sponsored by The Society of Thoracic Surgeons or by individual states. Only by unbiased entry of data on the outcomes of these endovascular procedures into a multi-institutional database will it be possible to accurately and efficiently monitor the results and thus provide optimal care to subsequent patients who will undergo these procedures.

\section{Technical Expertise \\ Recommendations}

The development and clinical application of new surgical techniques involves uncertainty and risk. It is essential that individuals who perform thoracic endovascular grafting procedures be experienced not only in the techniques required for those procedures but also in the traditional surgical procedures that are used to treat thoracic aortic disease. Listed below are five essential skills that physicians who perform thoracic endovascular stent-grafting procedures should possess. This experience can be obtained as part of an accredited cardiothoracic surgical training program.

1. Experience in the management of thoracic aortic disease by conventional open surgical techniques. The physicians should have completed an ACGME-accredited training program in which the surgical management of thoracic aortic disease is a primary focus. This experience is essential in order to provide objective information relating to all of the available therapeutic options to patients who are seen in consultation. It is equally important so that open thoracic surgical intervention can be provided in the event of a catastrophic occurrence during performance of the endovascular procedure. Dealing with urgent or emergent situations that may arise during performance of endovascular procedures requires considerable experience and ex- pertise. It is therefore recommended that prior to credentialing, physicians should have participated in a minimum of 10 open surgical procedures on the thoracic aorta in the previous two years.

2. Successful performance of a minimum of 25 catheter placements involving guide-wire technology and/or steerable catheters in the two years prior to credentialing. Expertise in these techniques is essential.

3. Participation in the successful placement of 10 abdominal or 5 thoracic aortic endovascular stent grafts.

4. Experience with placement of large-bore catheters into the femoral and iliac arteries.

5. Experience with retroperitoneal exposure of the iliac artery and performance of surgical procedures (bypass grafts, endovascular stents, etc.) on the iliac and femoral arteries.

\section{Pathways to Credentialing for Cardiothoracic Surgeons}

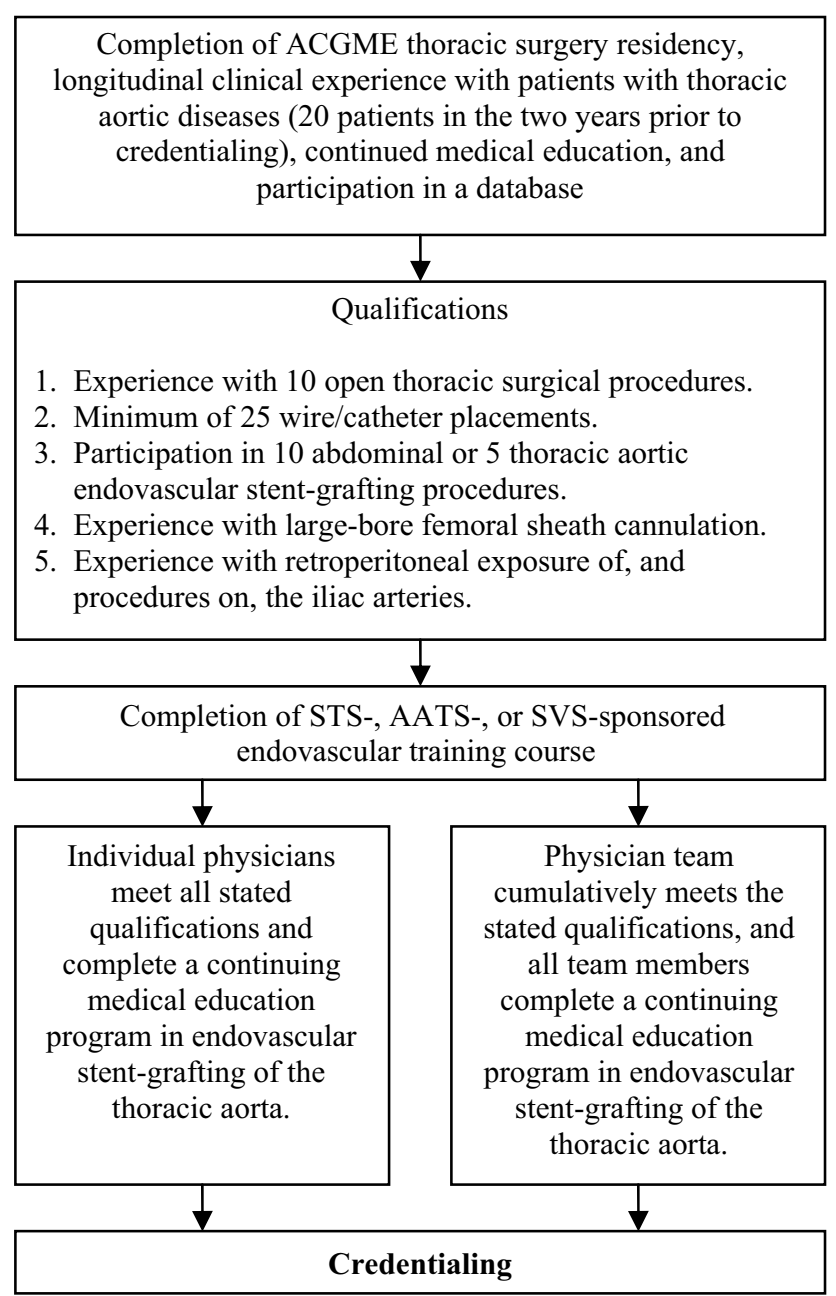


It is recognized that a single physician may not have the necessary experience and expertise in all 5 of the above categories. As a consequence, partnering with other physicians (vascular surgeons, cardiologists, interventional radiologists) who possess those skills that the applicant for credentialing may lack, is strongly encouraged, and represents a satisfactory model for establishing clinical programs dedicated to thoracic endovascular stent-grafting.

\section{Technique Specific Knowledge \\ Recommendation}

In addition to experience in the open surgical management of thoracic aortic disease and acquisition of the specific skills described above, additional educational activity is essential. Physicians seeking credentialing should participate in at least one course on thoracic endovascular stent-grafting sponsored by The Society of Thoracic Surgeons, the American Association for Thoracic Surgery, or the Society for Vascular Surgery. This could include, but should not be limited to, courses sponsored by industry that are endorsed by one or more of the above organizations. This didactic educational activity is essential to ensure that knowledge regarding thoracic endovascular stent-grafting is current and complete. These programs should provide physicians with opportunities to learn about different devices, information on newer models of the grafts, including their advantages and disadvantages, and the clinical applications of the devices. They should also provide an opportunity for physicians to exchange information with key leaders in the field of endovascular grafting.

As emphasized in the accompanying diagram, it is recognized that performance of endovascular surgical procedures for the management of thoracic aortic disease involves several skill sets that may not be present in a single individual. Although cardiothoracic surgeons are encouraged to obtain all of the necessary skills and knowledge to successfully perform these procedures independently, they may elect to participate as part of a team to implement this technology. By combining the expertise of physicians of different disciplines, each with specific skill sets, patient safety and the quality of care delivered will more likely be enhanced. Credentialing could thus be obtained by individual cardiothoracic surgeons or by teams of physicians that include cardiothoracic surgeons. 